\title{
EL SALVADOR: REFORMAS ESTRUCTURALES Y LUCHA CONTRA LA POBREZA
}

\author{
Sonia Ivett Sánchez 1
}

\section{Introducción}

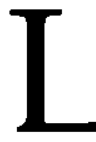

as deliberaciones sobre la necesidad de impulsar progra mas de estabilización y ajuste económico en la región son -por demás- muy obvias y repetidas. Los programas de ajuste estructural se instalaron como mecanismos concretos para reinsertar a las economías a las nuevas condiciones del mercado internacional mediante la modificación de las condiciones de la oferta. Esta modificación sustancial obedecía a la lectura que se hiciera de la denominada "década perdida", cuyo resultado fue una desaceleración de las tasas de crecimiento, altos niveles de desempleo y en general, la persistencia de severos desequilibrios macroeconómicos. En ese marco, en el mercado internacional se estaban operando grandes cambios que redundarian en un proceso de globalización económica a nivel mundial. Tal globalización presumía transformaciones profundas en la manera de abordar los problemas económicos, sociales, políticos y culturales de las sociedades del mundo.

En El Salvador, se experimentaron cambios importantes en materia de política económica dirigidos a consolidar el modelo de ajuste estructural, desde finales de 1989 hasta la actualidad. Desde tal modelo también se supuso la consolidación de nuevas bases de crecimiento económico.

Después de cinco años de estabilización e inicio del proceso de ajuste estructural, saltan por doquier las apreciaciones del buen 
desempeño económico de El Salvador. Diversos análisis económi$\cos ^{2}$ han concluido respecto al éxito del camino emprendido. Desde tales enfoques se suele pasar por alto los costos sociales que la estabilización y el ajuste han implicado; más aún, se reseñan con timidez y a título de hipótesis los presuntos aumentos en los niveles de pobreza y en consecuencia, el grave deterioro de las condiciones de vida de cerca de dos tercios de la población salvadoreña.

No obstante el optimismo con que se han asumido y pregonado los éxitos del modelo de estabilización y ajuste salvadoreño, persiste la preocupación sobre los magros resultados en materia social. Ahora en 1994, no sólo el nuevo Gobierno ${ }^{3}$ sino los organismos internacionales han reconocido la necesidad de ampliar y profundizar las acciones ya no solo de compensación social sino de carácter más integral y sectorial tendientes a combatir la situación de pobreza.

Abandonando el triunfalismo desaforado, ahora se asume conservadora y cautelosamente los éxitos y se los relativiza en función de los hechos que está mostrando la realidad social salvadoreña. Realidad social que -de suyo-impone el análisis reflexivo y crítico que aborde con seriedad y de manera estructural los problemas generantes de condiciones infrahumanas de vida de más del $57 \%$ de la población salvadoreña.

Sin embargo, la situación de pobreza en la que se debaten diariamente grandes contingentes de humanos no debe quedarse en el plano de las preocupaciones, la tarea impostergable se constituye entonces en el re-descubrimiento de medidas y acciones para abordarlo de manera que sea posible cambiar las condiciones estructurales que generan como resultado más pobres cada día. En tal sentido, es nuestra posición que la pobreza no podrá resolverse tan solo con política social, es imperativo - ante todo- la definición de una política económica de carácter sectorial capaz de generar empleo e ingresos para aquellos a los cuales su acceso está vedado por las condiciones estructurales de producción del país.

\section{Evaluación de los principales indicadores económicos 4}

e podría decir que en El Salvador se han dado pasos importan
tes en la etapa de la estabilización, la corrección de dese- 
quilibrios de corto plazo parecen estar controlados, pero esto.no es razón para dejar de mencionar la permanencia, todavía, de grandes desequilibrios en balanza de pagos. No obstante esos avances, en términos de ajustar la economía todavía hace falta la consolidación de medidas tendientes a cambiar las condiciones de la oferta. De esa manera, se requiere el fortalecimiento de la base productiva, la integración económica al interior y entre países de la región, el lanzamiento de la reconversión industrial, la promoción y diversificación de exportaciones y particularmente la diversificación de mercados. Amén de esas salvedades, los resultados económicos de El Salvador entre 1989 y 1993, que es cuando se instala un gobierno cuyo propósito económico central se basa en el impulso de un programa de ajuste estructural, se pueden verificar a partir de la enunciación de diversos indicadores, esto es: la economía experimentó un crecimiento promedio de $3.6 \%$ en el último lustro, y se proyecta para 1994 una tasa de $5.5 \%$. Vale decir que los sectores que muestran mayor dinamismo son el comercio y los servicios $(4.4 \%$ y $4.7 \%$ respectivamente entre 1990 y 1993), mientras que los sectores productivos como son la industria y el sector agropecuario han mostrado una tendencia marcadamente inestable.

La tasa de inflación promedio en el período 1989-1993 fue del $17 \%$, en 1993 la tasa bajó hasta $12.1 \%$ y para 1994 se presume que descendería 4 puntos más respecto al año anterior. En este aspecto se recalca que el índice de precios al consumidor para los alimentos en el mismo lustro registra una tasa promedio del $21.62 \%$. De ello se deriva que pese al control de la inflación, el crecimiento de los precios afectó con mayor rigor a los sectores cuya propensión al consumo es alta, es decir a la mayoría de la población.

El déficit comercial fue y sigue siendo cuantioso, entre 1989 y 1994 se tuvo una tasa promedio del 14\% como proporción del PIB y para 1994 se espera que represente el $15.1 \%$ del mismo rubro. Para 1993, el déficit comercial alcanzó la cifra récord de 1,100 millones de dólares equivalentes al $15.5 \%$ del PIB, más del doble del déficit de 1989; este comportamiento se podría explicar por el lento crecimiento de las exportaciones, especialmente la de productos tradicionales, y a la elevación del componente importado. A no ser que se operen cambios sustanciales en las variables de la ba- 
lanza comercial, este déficit continuará creciendo.

Mientras, el déficit del sector público no financiero alcanzó la tasa promedio de $2.7 \%$ del PIB incluyendo donaciones y sube a $4.6 \%$ si se excluyen. Esta situación alerta respecto a la dependencia de recursos externos para la reducción de esta importante brecha.

El modelo económico adoptado es el que se rige por las leyes de oferta y demanda; sin embargo, en El Salvador, se ha guardado discrecionalidad respecto a algunas variables que desde el modelo harían suponer decisiones opuestas. Por ejemplo, la abundancia de recursos externos característicos del período en cuestión, habría llevado a que el tipo de cambio bajase, sin embargo la política monetaria y crediticia apoyó, sin más, una sobrevaluación de la moneda. El exceso de liquidez anunciaría la disminución de las tasas de interés, no obstante se han mantenido en niveles muy superiores al que establecerían, precisamente, las condiciones del mercado.

Los niveles de inversión privada llegaron a $11.58 \%$ en promedio entre 1989 y 19935, mientras que la inversión pública se mantuvo en al rededor del 3\%. No ha habido incrementos importantes de la inversión en su totalidad. Con niveles inferiores al $20 \%$ respecto al PIB, como es ahora, difícilmente se puede mantener el crecimiento económico de manera sostenible. A esto se agrega el hecho de que las inversiones se concentraron en sectores poco productivos como el comercio y los servicios. La inversión en la agricultura y la industria fue mucho menos dinámica. Esta puede ser otra explicación al repunte de los servicios y el comercio en su participación en el PIB.

Un último indicador macroeconómico que señalamos es el referido a la carga tributaria, la tasa promedio en el período 1989-1993 fue de $8.48 \%$, en él ya está considerado el repunte que se esperaría de la reforma tributaria adoptada en 1992, mientras que para el período 1980 y 1988 la tasa promedio de carga tributaria fue del $11.2 \%{ }^{6}$. Un dato interesante lo constituye el hecho de que en 1993 se alcanzó la carga tributaria más alta de ese período (9.4\%), muy similar al porcentaje más bajo del período de la crisis, $9.3 \%$ en 1988. Los datos indican que en época de crisis se tuvo mayor capacidad de captación y tributación, mientras que en la "etapa de 
estabilización y reactivación económica" la economía no fue capaz de aportar más en términos de impuestos.

\section{Distribución de costos y beneficios}

F $n$ El Salvador, para 1989 , el $55.2 \%$ de los hogares urbanos se breza extrema y $31.9 \%$ en pobreza relativa. Para 1992/93, se reportó el $57.5 \%$ a nivel global, el $30.5 \%$ en condición de pobreza relativa y el $27 \%$ en pobreza extrema. En consecuencia, según las cifras oficiales, en términos globales tanto absolutos como relativos hubo un incremento en los niveles de pobreza.

Del total de la población económicamente activa ocupada, para 1993 el $47 \%$ se encontraba en el sector informal; los salarios mínimos reales tuvieron en todos los años, a excepción de 1993, tasas de crecimiento negativo, siendo los más afectados los salarios del sector agrícola. Por su lado, una de cada diez personas en edad de trabajar no tenían empleo, el 50\% de los niños menores de 5 años padecían algún grado de desnutrición, la mortalidad infantil era de las más altas de América Latina, más del $27 \%$ de la población mayor de 15 años se encontraba en situación de analfabetismo; el $45 \%$ de la población no tenía acceso a agua, en el campo esta carencia se incrementó a $63 \%$; finalmente el $41 \%$ del total de población carecía de servicios sanitarios.

Referido a la distribución del ingreso es evidente una estructura desigual. Según el Ministerio de Planificación, el grupo de población urbana que experimentó el mayor crecimiento de ingreso real en 1992 fue el $10 \%$ con ingresos más altos y el grupo cuyo ingreso creció en menor proporción fue el correspondiente al $10 \%$ más pobre. Los mismos datos revelaron que el 10\% más pobre de la población urbana vio reducido su ingreso real en 1991, mientras el segundo decil reflejó que el ingreso se estancó.

En función de los datos macroeconómicos y 'macrosociales' supra tratados, es obvio que un balance de ambas variables merece reservas. Así, no se sostiene que los patéticos resultados en materia social sean imputables en su totalidad al proceso de estabilización y ajuste, pero no se puede negar que en tal período hubo una tendencia a su agravamiento. En ese sentido, si la pobre- 
za tiene raíces estructurales conformadas históricamente en el país y la estabilización y el ajuste como modelo económico prevaleciente no parece proporcionar las respuestas necesarias; entonces, es claro que hace falta abordar el problema con seriedad desde ahora, de una manera tan radical como así lo demanda la realidad, y no dejar a la posteridad semejante tarea.

Por su lado, el gasto social como proporción del presupuesto nacional alcanzó en promedio el $25.5 \%$ entre 1989 y 1992 y como proporción del PIB 3.17\%, ambas denotan la poca relevancia que el sector social representó en el período. Como ejemplo, la ayuda externa en el área social representó en el mismo período el $3.3 \%$ del PIB, lo cual viene a mostrar que hubo mayor interés de la cooperación externa por atender este sector que del lado del interés nacional. Esta afirmación cobra vigor si tales porcentajes - se sabe- son muy inferiores al de muchos países de América Latina y no se diga de Europa?.

Los sectores sociales más importantes como son educación y salud, sufrieron cuantiosas reducciones. Entre 1989 y 1992, el gasto público en educación representó al rededor del 13\% en promedio del presupuesto y el sector salud apenas fue del $6 \%$ para el mismo período. La participación de dichos sectores en el PIB, apenas llegó a ser del $1 \%$ en salud y $1.5 \%$ en educación para 1993. Tales datos dan evidencia de la poca atención que el sector social mereció en las prioridades gubernamentales, en un período donde se supuso que los únicos privilegiados del gobierno serían los más pobres de los pobres.

Las medidas de estabilización que mayor impacto previsible tendrían sobre amplios sectores de la población se relacionan a los recortes a los subsidios, los cuales se tradujeron en incrementos sobre los precios de la energía eléctrica, servicios de agua, telefonía, transporte público, eliminación de controles de precios a los productos de la canasta básica. En general, estos incrementos de precios afectan a todo el que lo consume, sin embargo, aunque no hayan estudios particulares por segmentos poblacionales según ingreso, es de esperar que el impacto mayor lo hayan recibido, los sectores cuyos ingresos son más bajos. Habría que probar las diferencias por áreas geográficas, urbano y rurales. Pero lo que no se puede negar, aún con falta de información, es un impacto perver- 
so sobre el poder de compra de los más pobres.

Los incrementos en los niveles de pobreza dan muestra de que la política compensatoria seguida por el gobierno, no fue efectiva para disminuir su nivel.

Respecto al impacto de otro tipo de reformas estructurales, los resultados todavía están sujetos a verificación, por ello lo único que se aventura son presunciones. Así, con el proceso de liberalización comercial, es posible suponer un incremento del consumo de bienes importados cuyos precios son más bajos en el exterior; pero es difícil pensar en que esto favorece a los más pobres dado que su posibilidad de consumir bienes importados es poco significativa. Por otro lado, la disminución de aranceles y trabas no arancelarias podrían provocar una contracción del empleo si el sector de sustitución de importaciones no es suficientemente competitivo, habría que verificar este tipo de impactos por ramas industriales (ejemplos: industria textil, calzado, productos farmacéuticos, etc.). Si el efecto es una contracción del nivel de empleo, obviamente la apertura comercial no será beneficiosa para los trabajadores ni para las empresas que resulten ineficientes.

En el mismo sentido, si los procesos de privatización de empresas propiedad del estado, encarnan despidos masivos y no hay condiciones para absorber productivamente este flujo de desempleados, obviamente la medida tendrá un efecto negativo sobre un sector muy específico, esto es los trabajadores. Estas situaciones, no obstante, implican valoraciones específicas dependiendo de cómo se ejecute la privatización. Así, si a partir de ella se cede a los trabajadores la facultad de operar las máquinas, de continuar con la actividad productiva específica, no tiene porqué haber cambios importantes en los niveles de empleo. Otro efecto es el que pueden significar las indemnizaciones por despido puesto que estos recursos se podrían canalizar productivamente, pero también se podrían usar en consumo. $\mathrm{Si}$ aconteciera este último resultado simplemente habría incrementos temporales en los niveles de consumo de los beneficiados pero en el mediano plazo, lo más probable es que si no se emplean, engrosen las filas de los pobres.

Como efecto global, no parecen haber dudas respecto a la perversidad del modelo de estabilización y ajuste para afectar a los 
sectores vulnerables. Vale decir que desde el modelo no se intenta dar soluciones verdaderas a los problemas de pobreza, la política de compensación inmersa en la política social no parece ser suficiente ni para disminuir ni erradicar la pobreza. De hecho, nuestra posición es que en el país no hay una política definida para afrontar el problema de la pobreza. En consecuencia, si no se remueven las condiciones estructurales que crean pobres, las medidas siempre serán insuficientes porque no atacan sus raíces sino sólo sus manifestaciones.

Para palear los efectos nocivos emanados del programa de ajuste, el gobiemo crea 2 instituciones encargadas directamente de atender el a los sectores más pobres, de una manera compensatoria y focalizada. Así, se creó el Fondo de Inversión Social en 1991, con el propósito de "aliviar las condiciones de pobreza en la que vive gran parte de la población, satisfaciendo sus necesidades básicas más apremiantes". El propósito es explícito en cuanto pretende aliviar no resolver la condición de pobreza de la población. Las medidas de erradicación no aparecen en los planes sino que siempre se le heredan al próximo gobierno con el pretexto de que se trata de un problema de larga data, por eso mismo debería ser prioritario comenzar a combatirlo desde ya y no dejarlo para el mediano y largo plazo.

El FIS contó con aproximadamente 120 millones de dólares (desde su nacimiento a junio de 1994) para la ejecución de sus proyectos. El grueso de ese financiamiento provino de fuentes extemas en calidad de préstamos. Del grueso de la ayuda, al rededor de 90 millones de dólares, se originaron en préstamos del BID otorgados al gobiemo central; 20 millones corresponden a financiamiento del gobierno central y el resto proviene de diversas fuentes.

A junio de 1993, el FIS había aprobado 3,114 proyectos por un monto de 423 millones de colones, de ellos sólo estaban terminados $19.8 \% ; 24.2 \%$ se encontraban en ejecución, el $15.0 \%$ estaban pendientes de inicio y el resto estaban en promoción. El total de proyectos ascendía a 5,283 entre aprobados y en promoción $n^{8}$.

Del total de proyectos aprobados por el FIS, 1,176 equivalentes a $37.8 \%$ estaban destinados al sector educativo, a salud y nutrición correspondió el $37.4 \%$ (1,166 proyectos) y el restante $24.8 \%$ (772 
proyectos) se destinaron a la construcción de cocinas, forestación y otros ${ }^{9}$.

La ejecución de proyectos por parte de FIS, se rigen bajo criterios de focalizar la ayuda a los más necesitados; promover la participación de la población en el desarrollo de los mismos; se guían por la "demanda"; es una gestión autónoma que sortea el problema de la burocracia estatal y por último intentan evaluar sus proyectos.

Los señalamientos que se hacen a la gestión del FIS aparte de la consideración inicial de que no es con compensación como se resolverán definitivamente los problemas de pobreza en el país, son:

a. La dependencia casi exclusiva de préstamos del exterior, esto permite hacer al menos tres acotaciones: i) Los préstamos implican para el país una carga futura en el servicio de la deuda. De aquí que no es suficiente publicitar sus resultados como tan falazmente se ha hecho, sino que implica que el país tiene que pagar en un futuro próximo los costos de la compensación; ii) Las condicionalidades derivadas de las fuentes de financiamiento externas, establecen restricciones para la decisión en la orientación de los proyectos y iii) Una vez las fuentes cesen, peligra la existencia del FIS y su consecuente labor.

b. La aplicación del criterio de focalización en un país cuyo porcentaje de pobreza azota al $57 \%$ de la población justifica la falta de compromiso serio por abordar el problema y encubre el derecho humano fundamental de que cada salvadoreño tenga una vida digna y satisfaga adecuadamente, al menos, sus necesidades básicas.

c. El carácter compensatorio y por tanto coyuntural de sus programas. Esto significa que la pobreza estructural no ha sido y tampoco piensa ser abordada por esta institución.

d. El FIS se guía por el criterio de la "demanda" para la aprobación de sus proyectos. La posibilidad que sean los más pobres los que tengan la iniciativa para acercarse a la institución y no al revés, para la resolución de sus problemas es muy baja.

e. La desagregación de los proyectos que el FIS hace a la fecha permiten inferir que sólo la quinta parte de sus proyectos está 
terminado, con lo cual se muestran dificultades de ejecución.

La Secretaría de Reconstrucción Nacional se creó al tenor de la creación del Plan de Reconstrucción Nacional, resultado de la firma de los acuerdos de paz $^{10}$. El PRN contemplaba la realización de dos fases: la de contingencia y la de consolidación. En ambas se definieron 4 tipos de programas: los de infraestructura básica, desarrollo social y productivo, apoyo a la reinserción de desmovilizados, administración y programas de alimentos.

El PRN concluyó la fase de contingencia, a través de la cual se ejecutaron 8,418 proyectos con un valor de $\$ 27.08$ millones, aunque inicialmente se había presupuestado la realización de obras por casi el doble. A partir de 1992, se inició la fase de mediano plazo, cuyo horizonte es de 5 años y para la cual ya se habían asignado $\$ 74.2$ millones y ejecutado $\$ 30.6$ millones a mayo de $1993^{\prime \prime}$.

A la SRN se le hacen los mismos señalamientos que pudieron advertirse en el caso del FIS. Hay un señalamiento adicional en este caso, y es la presunción del carácter político que parece aplicarse en la asignación de recursos por parte de la Secretaría, esto podría obedecer a que, en muchos casos, la ejecución de proyectos se hace a través de los gobiernos municipales, los cuales tienen un claro vínculo político con el gobierno central.

Por otro lado, en el sector educativo ha habido una experiencia que amerita revisión, esto es, el programa de Educación con Participación de la Comunidad (EDUCO), dicho programa presenta la cualidad de generar participación de la población beneficiaria en la supervisión de los proyectos, además de constituir un mecanismo sencillo para la ampliación de cobertura a nivel de educación básica particularmente de primero a tercer grado ${ }^{12}$. No obstante, cabe señalar su poca efectividad para la ampliación en la cobertura, apenas se ha atendido 52,000 niños a través de alrededor de 1,200 asociaciones comunales con un costo de 36.5 millones de colones. También cabe advertir que este proyecto se desarrolló exclusivamente con préstamos externos, aunque se estima que para 1993 el Gobierno de El Salvador habría absorbido el 30 por ciento de los costos del programa y para 1994 el 100 por ciento, a cambio el Banco Mundial gastaría 43 millones de colones para capacitar personal e instalar un nuevo sistema de información en el Ministe- 
rio de Educación. ${ }^{13}$ Este hecho marca un problema importante, en cuanto que ahora no solo se tendrá que financiar el programa con recursos nacionales, sino que además deberá destinarse cierto monto al pago de la deuda.

En el sector salud se cuenta con los Sistemas Locales de Salud (SILOS). La idea consiste en acercar los servicios de salud a la comunidad, en consecuencia implican gran participación en la toma de decisiones por parte de la comunidad. En los últimos años se han desarrollado - también con fondos externos- 5 SILOS, parece ser que han tenido un desarrollo desigual entre si, sin embargo la experiencia merece ser revisada a efectos de mejorar sus potencialidades, especialmente aquella que tiene que ver con el desarrollo de una buena coordinación interinstitucional. ${ }^{14}$

Las experiencias hasta aquí mostradas dan cuenta por un lado, de la gravedad de los problemas de pobreza que se viven en El Salvador y por otro, de las dificultades que tiene el gobierno para expandir los programas de combate a la misma.

Las reformas estructurales emprendidas no parecen tener como prioridad la solución de los problemas de pobreza, la lógica radica en la búsqueda de mecanismos de reinserción al mercado internacional, aún cuando en ello se arriesgue un alto costo a ser pagado especialmente por los grupos más vulnerables.

\section{Efectos políticos de las reformas y de los programas de amortiguación de los costos sociales}

L

a ejecución de las reformas estructurales tiene un claro costo social, y un no muy claro efecto político. Las preguntas significativas son: ¿quién paga los costos sociales?, ¿de qué manera?, ¿quiénes son sus mayores adversarios y por qué?

La implementación de las reformas estructurales ha implicado el pago de diversos costos. Obviamente los grupos afectados negativamente por la adopción de ciertas medidas se presentarán como los principales adversarios. Así por ejemplo, retomando el proceso de privatización y reducción del papel del Estado en la actividad económica, evidentemente los grupos con mayor resistencia están asociados al sector laboral formal, esto es empleados públicos, docentes, personal paramédico y sindicatos. Esta cuestión es compren- 
sible dado el efecto directo que sobre estos sectores podrían tener las medidas contraccionistas. Sin embargo, los efectos netos son difíciles de valorar en ausencia de datos, por ello queda hacer presunciones. En tal sentido depende de las características propias de la privatización, si incluye indemnizaciones su efecto podría significar una reorientación hacia actividades productivas o consumo puro, si encarnan despidos masivos, habrá una tendencia al desempleo si en la economía no se crean nuevas formas de absorción productiva.

Otro sector afectado por las reformas estructurales que podría plantear oposición, se refiere a aquellos empresarios con poca capacidad competitiva, sobre todo la micro y pequeña empresa con dificultades reales de reconversión ante la apertura comercial. Estos grupos y sus asociaciones gremiales con regularidad se opondrán al ajuste.

Otro tipo de políticas como la reducción y eliminación de subsidios no afecta directamente a un grupo homogéneo de la población, sino a aquellos sectores usuarios de los "bienes públicos", estos procesos se traducen en descontento popular no siempre canalizado en el corto plazo, pero se expresa en un deterioro en las condiciones de vida de la población afectada.

Los programas orientados a hacer frente a los costos sociales de las reformas estructurales por el lado del Gobierno se refieren al FIS y al PRN y a algunos intentos por vincular las actividades de los Ministerios de línea con acciones de combate a la pobreza. En general, la cobertura de las instituciones existentes a esos efectos, tienen un desarrollo muy exiguo y con regularidad ofrecen servicios de mala calidad. Por ello si no son capaces de remover las condiciones que tipifican a diversos grupos como pobres extremos o pobres relativos su actuación no será suficiente.

En este contexto se plantea la siguiente reflexión, la tendencia es que los diversos servicios públicos tradicionales (salud, telefonía, energía eléctrica, etc.) pasen a ser prestados por la empresa privada. Independientemente de la opinión de que sector privado no es equivalente por definición a eficiencia, la acotación es que el tradicional sector público pasa a ocupar un papel normador. Es decir, que se le concibe como el ente que tendrá, entre sus funciones, la 
facultad de generar los marcos regulatorios idóneos para garantizar, buena calidad, efectividad y eficiencia en la nueva forma de prestación de servicios. Sin embargo, no hay razones para derivar tan simplistamente que el sector público que no pudo ser buen administrador de sus propios bienes, de garantía de velar correctamente por la prestación de bienes que ahora serían ajenos.

En términos del combate a la pobreza, en el sociedad salvadoreña se entrecruzan dos fenómenos que ameritan atención: el papel que puedan desempeñar en este sentido más de 200 ONG's y los cuantiosos montos de ayuda externa ya sea en concepto de donación o remesas. En relación a lo primero, somos de la opinión que aunque hay ONG's cuyo principal mérito ha sido el enriquecimiento y el acceso a privilegios de parte de quienes las manejan, también las hay quienes han hecho verdaderas contribuciones en la tarea de resolver algunos problemas de pobreza. No es desdeñable el papel que este importante sector haya desempeñado a lo largo de período del conflicto como en su posguerra.

Asimismo como no es imputable a la estabilización toda la culpa de la presencia de pobreza, tampoco se le puede atribuir exclusivamente la bondad de los equilibrios macroeconómicos. En relación a este punto, mucho han contribuido las remesas de los salvadoreños en los Estados Unidos y la ayuda extema. Las remesas han superado incluso el monto global de las exportaciones de 1993 y la ayuda externa representó el 6.6\% del PIB entre: $1989-1992 .{ }^{15}$

El análisis de esos fenómenos podría significar cambios en la manera de interpretar la cuestión de los resultados macroeconómicos y hallazgos sustanciales en la forma de cómo abordar el problema de la pobreza en el país.

En suma, cada medida tendrá su beneficiario y su adversario, nosotros sostenemos que el grueso de medidas afectan de manera negativa a la población pobre del país. Entonces, lo que está en juego en el futuro próximo es qué costo político se comenzará a cobrar al gobierno. Al menos en El Salvador hay demostraciones de descontento que pueden conducir a un problema de gobernabilidad. Si no se adoptan medidas tendientes a abordar los problemas de pobreza, entonces puede estar en juego la viabilidad del modelo en términos económicos, sociales y políticos. 
IV. Lecciones de estas experiencias: ¿Cómo deberían estructurarse los programas para la amortiguación de los costos sociales?

L

os programas de combate a la pobreza no deben estructurarse tiguando como se resolverá el problema seguramente habrá que comenzar desde ahí, pero no debe implicar la renuncia a una estrategia más amplia, de largo plazo y definitiva. En consecuencia, se impone la necesidad de crear una estrategia económica y social que elimine la exclusión a que son sometidos más del $57 \%$ de la población salvadoreña. Se reivindica entonces la estructuración de una política integral económica-social de combate a la pobreza. Esa dualidad económica-social no deberá entenderse como epítetos teóricos que favorecen a la retórica, sino como la fusión inextricable de dos dimensiones indisolubles e interdependientes. Es decir que, sobre la base de la integralidad, de un enfoque sistémico, se responda de manera estructural, definitiva y operativa en el abordaje del mayor flajelo del siglo actual: la pobreza.

La manera operativa de cómo estructurar programas de erradicación de la pobreza, implican para El Salvador, el conocimiento democrático y generalizado de las condiciones reales de privación que padecen muchos salvadoreños. Es decir, el diagnóstico de la situación real de pobreza en el país debería ser de conocimiento público para que los diversos actores sociales puedan dar pasos firmes en su erradicación. No es posible que la tecnocracia gubernamental sea la única capaz de, conocer, definir e identificar a los pobres y mucho menos la única llamada a abordar sus problemas.

El problema de la pobreza no debe resolverlo únicamente el Estado, a través de su Gobierno. Esto por un principio elemental de limitación de recursos y por la complejidad que su solución entraña. Es un fenómeno que requiere del compromiso de la empresa privada y de otros sectores de la sociedad de una manera coordinada e integral. Tal iniciativa significaría la creación de instancias de coordinación macrosocial multidisciplinarias, e instancias de ejecución regionales o zonales.

En esa perspectiva debe redimensionarse el papel del Estado en su acción de combate a la pobreza, pero además el resto de actores sociales deberán ir asumiendo su responsabilidad en su abordaje. 
En las agendas de trabajo de las instancias comprometidas con la erradicación de la pobreza habrá que partir del establecimiento de prioridades en la definición de la estrategia. Nosotros consideramos que tienen que existir dos ejes, el primero que parta de una visión macroeconómica y macro social en la que se definan prioridades, fuentes de financiamiento, áreas de acción, formas de coordinación, etc. El segundo eje debe de partir de las iniciativas locales. Se ha evocado la participación de la comunidad como protagonista en la solución de sus problemas de pobreza, ella sin embargo ha estado tipificada por una participación pasiva, como dotadores de "horas de trabajo" y no como gestores, decisores y ejecutores de sus proyectos. Estamos convencidos que a nivel local existen ya experiencias más efectivas de erradicación y combate a la pobreza, lo que ocurre es que no las conocemos. El secreto estaría entonces en cómo potenciar esas iniciativas exitosas. ${ }^{16}$

Para la definición de prioridades, en los programas de combate a la pobreza están claramente definidas las siguientes: garantizar la provisión de servicios básicos: agua potable, saneamiento, energía eléctrica; garantizar la educación básica y media a toda la población, sobre todo para población del área rural; consolidar la atención preventiva en salud; establecer una red de previsión social que incluya al llamado sector informal; caminar en la descentralización de decisiones y recursos y mejorar los programas de compensación social, entre otros.

Estas ideas no obstante, solo serán una quimera si las diversas iniciativas qué existen no se traducen en acciones concretas para abordar con seriedad y de manera estructural el problema de la pobreza. El reto está planteado y cada uno de nosotros tiene la responsabilidad de contribuir desde su propio trabajo, profundizando la naturaleza de su quehacer institucional en la tarea de construir una sociedad más justa y equitativa.

\section{NOTAS}

1. Jefa del Departamento de Economía de la UCA.

Este artículo constituye una ampliación de la ponencia presentada en el Seminario "Reformas Estructurales y Lucha contra la Pobreza", organizado por el Centro Interdisciplinario de Estudios sobre el Desarrollo Latinoamericano. San José Costa Rica, octubre de 1994. 
2. Se destacan las apreciaciones de la Fundación Salvadoreña para el Desarrollo Económico y Social, el mismo Gobiemo, la CEPAL y diversos organismos internacionales.

3. El discurso inaugural de toma de posesión a la Presidencia de la República del Dr. Calderón Sol, destaca el empeño que pondrán en el abordaje de problema de la pobreza y asegura que en su gestión se deberá romper con el estigma de que el que nace pobre esté condenado a morir pobre. El Diario de Hoy, Junio 2 de 1994.

4. Los datos presentados en esta parte aparecen en anexo, o en su defecto fueron procesados a partir de las cifras de Cepal en su informe sobre "El Salvador: Evolución Económia durante 1993.

5. En el cálculo de este promedio se incluye la variación de inventarios.

6. Baires, J. y Orellana, A. "Análisis de traslación de excedentes intersectoriales: implicaciones para la determinación de bases fiscales". Tesis de Economía 1994. UCA, p. 20.

7. Sánchez, S. I. Ayuda Externa y Evolución de Indicadores Sociales, 19731992. Documento de Investigación del Departamento de Economía de la UCA. 1994.

8. FIS, Informe de Avance $N^{\circ} 24$.

9. Ibid.

10. La Secretaría de Reconstrucción Nacional SRN, fue creada por Decreto Ejecutivo $\mathrm{N}^{\circ} 8$, publicado en el Diario Oficial $N^{\circ} 39$, tomo $N^{\circ} 314$ de fecha 27 de febrero de 1992, como estructura administrativa adscrita a la Presidencia de la República, cuyo propósito general era ejecutar el Plan de Reconstrucción Nacional.

11. Plan de Reconstrucción Nacional: su impacto en la economía nacional, 1992 1993. Arguello, A. y Granillo, R. Revista Realidad Económico Social, $\mathbf{N}^{\circ} 36$, 1993, p. 612.

12. Veáse Evaluación del Programa EDUCO. MINED, 1992. También se reconoce que existe la tendencia de los maestros a querer insertarse en el sistema formal de escalafón (Ley de Salarios), y no quieren ser empleados de la comunidad. Dicha situación es comprensible debido a razones de seguridad social.

13. Diagnóstico del Sistema de Desarrollo de los Recursos Humanos en El Salvador, IIH, FEPADE, UCA, pág. 28.

14. Veáse la sistematización que hizo la Agenciả de Cooperación Italiana. El SILOS Sur, 1993.

15. Op. cit., Ayuda Externa y Evolución de Indicadores Sociales, p. 22.

16. Para este efecto revisar: A. Montoya. La Nueva Economía Popular: una aproximación emplrica. UCA Editores 1994. 


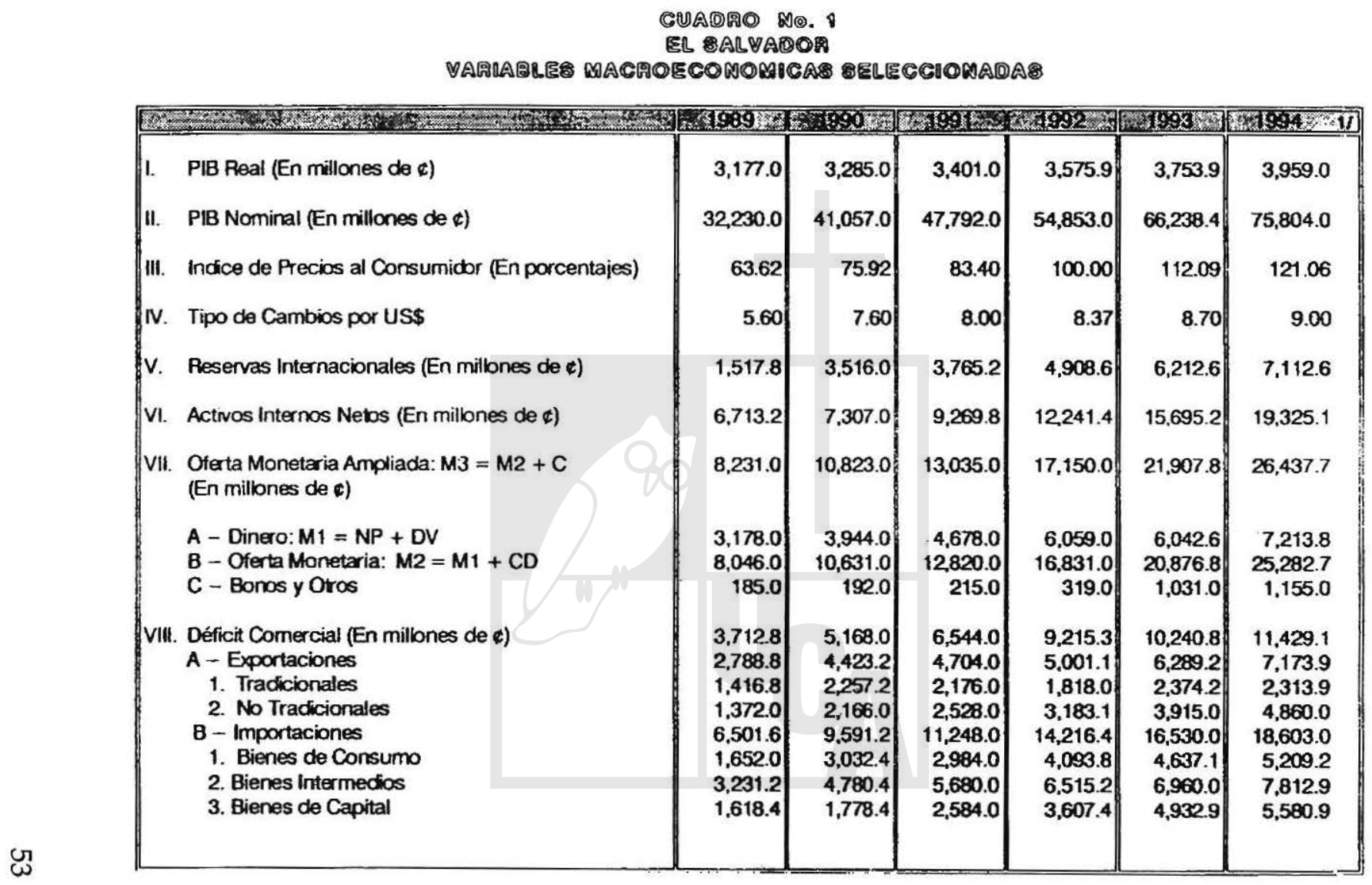




\section{GUADRO W०. \\ ER SARBADOR \\ VAPRADRES WAGROEGONOWNGAS SELECCHONADAS}

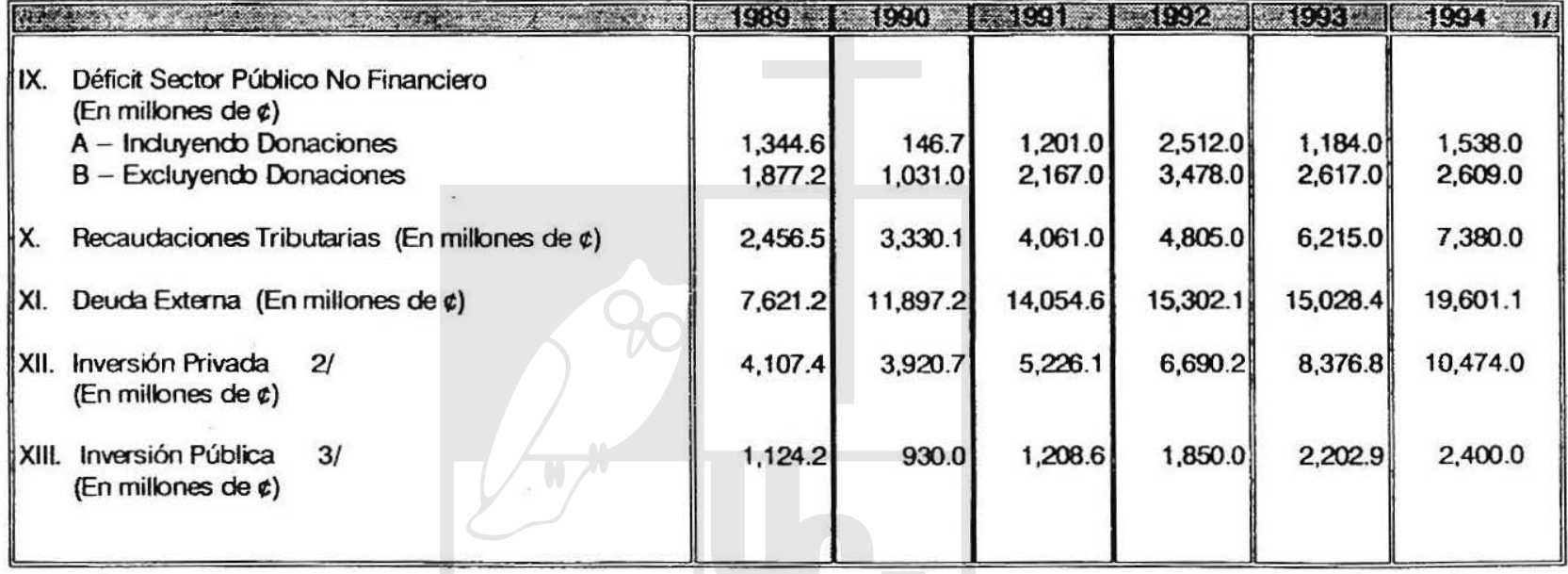

\section{$1 /$ Proyectado \\ $2 /$ Incluye variación de inventarios \\ 3/ Retomada de cuentas Nacionales}

PUENTE: Banco Central de Reserva, Revistas, Reportes de Liquidez y otros. 


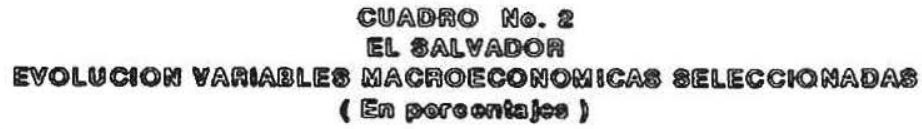

( Em Doromiaje )

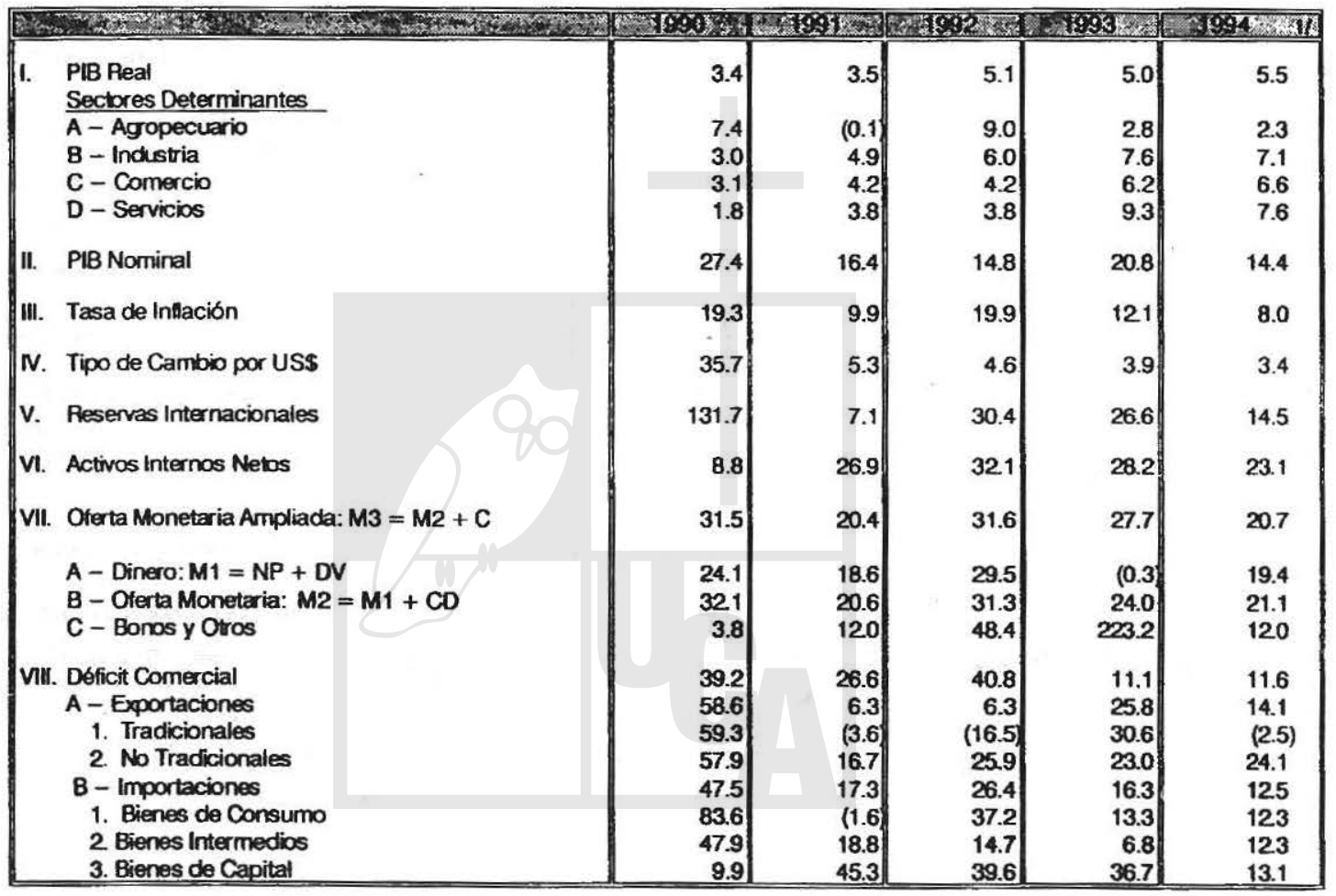




\section{CUADRO WO. 2 \\ EL BALVADOR \\ EVORMGON YAROARES MACROEGONOMNGAS BELEGCOONADAB

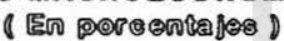

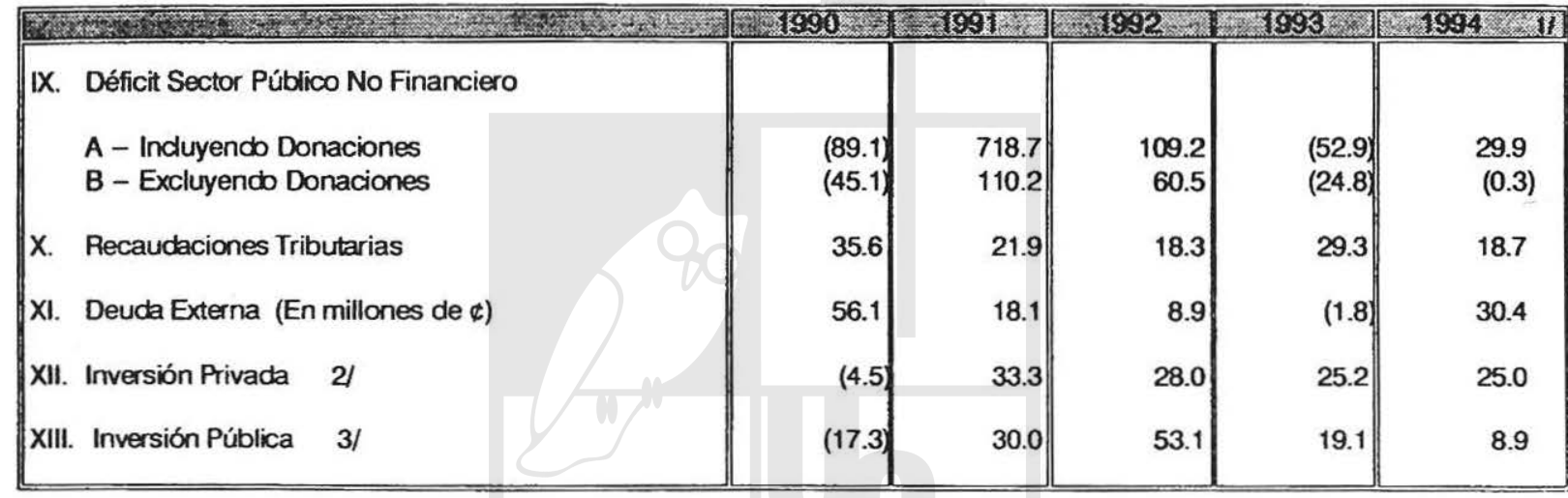

\section{1) Proyectado}

$2 /$ Incluye variación de inventarios

$3 /$ Retomada de Cuentas Nacionales

FUENTE: Cuadro No. 1 


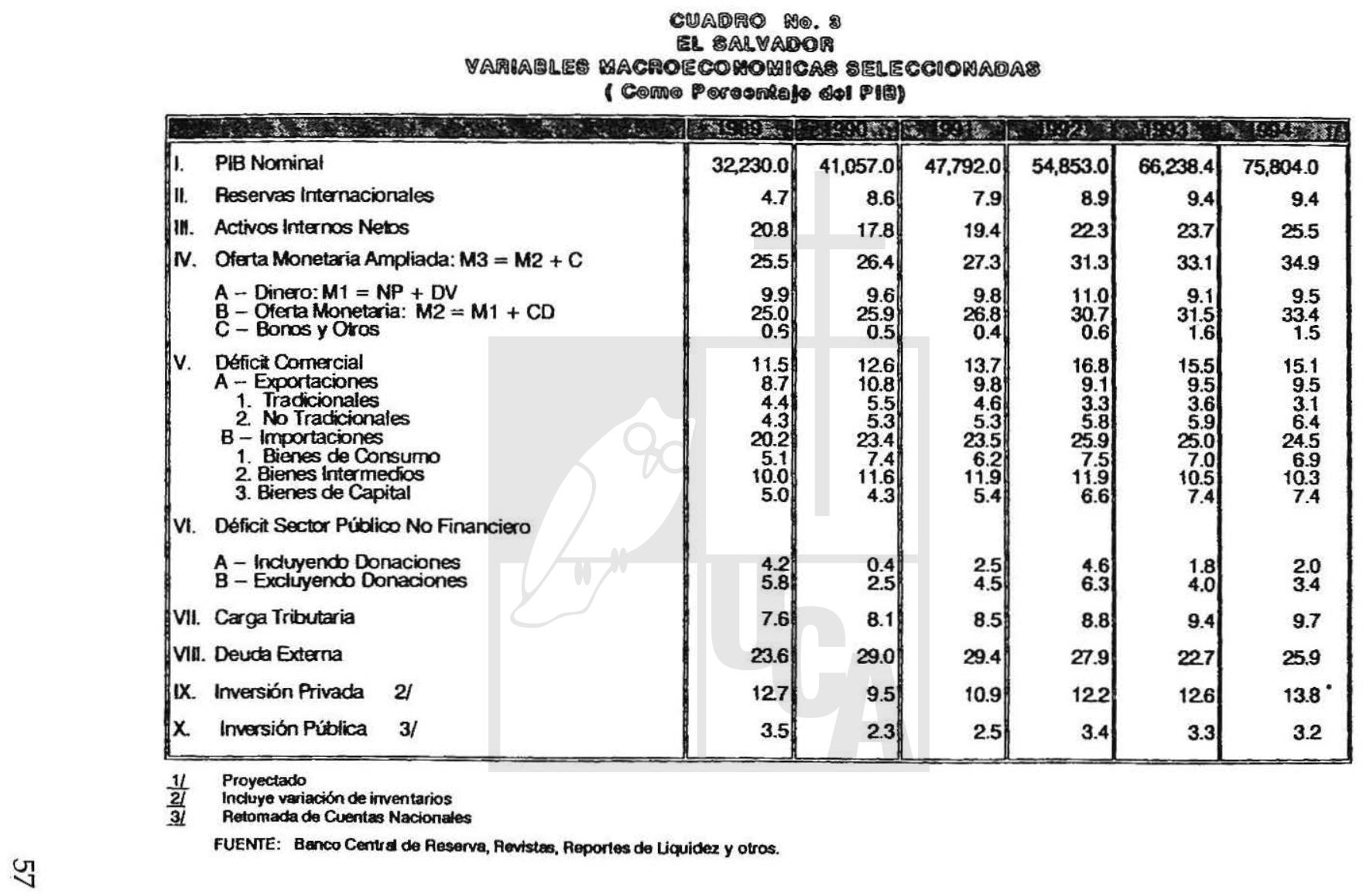

Digitalizado por Biblioteca "P. Florentino Idoate, S.J."

Universidad Centroamericana José Simeón Cañas 


\section{CบADRO MO. 4 \\ EL SALVADOR \\ YARAALLE MACROECOMOMUCAB BELECMONAOAE \\ ( 5 ต ตั0}

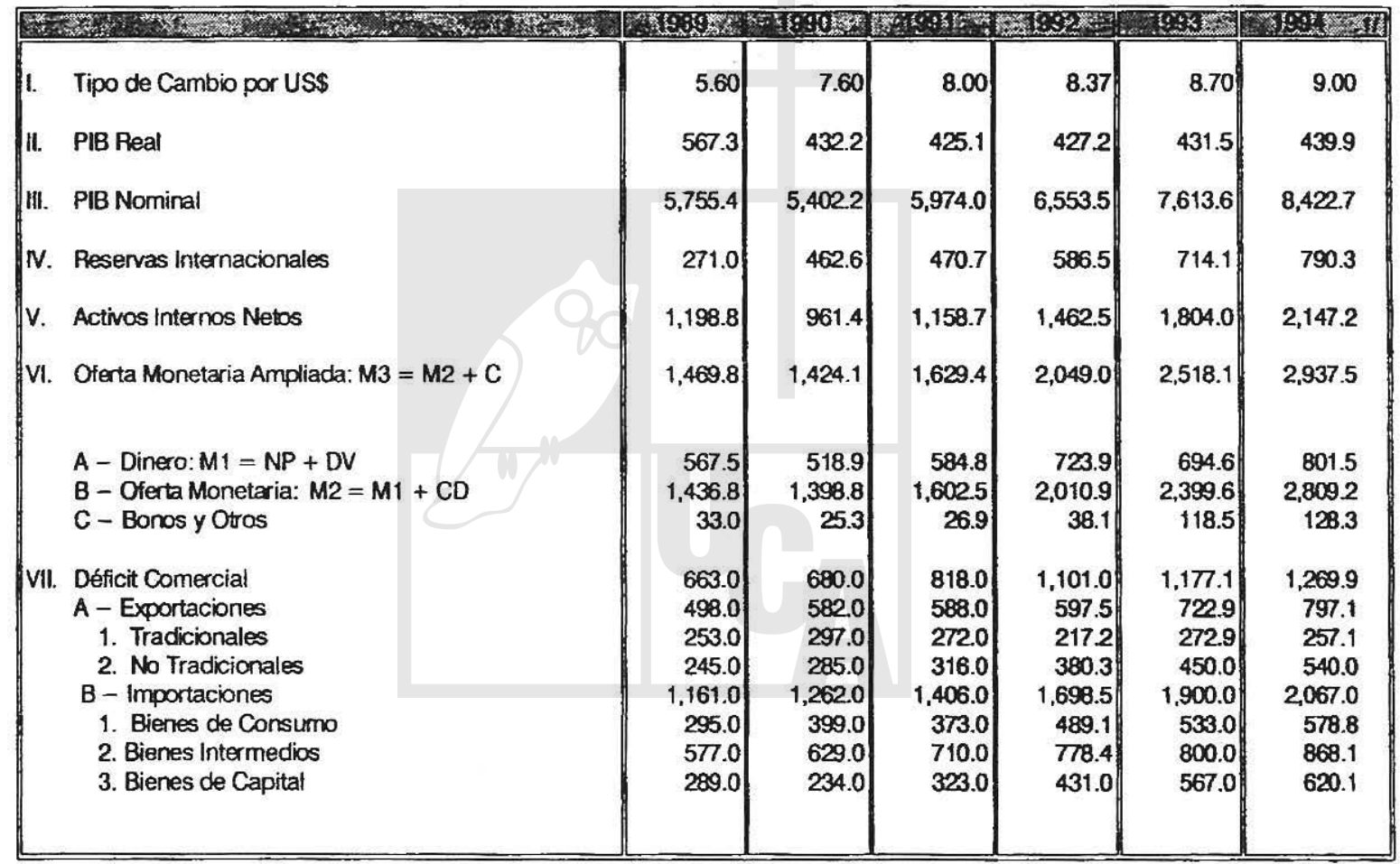

Digitalizado por Biblioteca "P. Florentino Idoate, S.J."

Universidad Centroamericana José Simeón Cañas 


\section{GUADRO M๑. 4 \\ E⿰ BALVADOR \\ VARHARLES MACROECONOMUAS SELEGCHONADAS

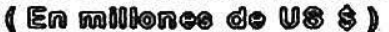

\begin{tabular}{|c|c|c|c|c|c|c|c|}
\hline \multicolumn{8}{|c|}{ HF } \\
\hline \multicolumn{8}{|c|}{ VIII. Déficit Sector Público No Financiero } \\
\hline & $\begin{array}{l}\text { A - Induyendo Donaciones } \\
\text { B - Excluvendo Donaciones }\end{array}$ & $\begin{array}{l}240.1 \\
3352\end{array}$ & $\begin{array}{r}19.3 \\
1357\end{array}$ & $\begin{array}{l}150.1 \\
2709\end{array}$ & $\begin{array}{l}300.1 \\
415.5\end{array}$ & $\begin{array}{l}136.1 \\
3 m 8\end{array}$ & 170.9 \\
\hline IX. & Recaudaciones Tributarias & 438.7 & 438.2 & 507.6 & 574.1 & 714.4 & 820.0 \\
\hline & Deuda Externa & $1,360.9$ & $1,565.4$ & $1,756.8$ & $1,828.2$ & $1,727.4$ & $2,177.9$ \\
\hline & Inversión Privada $2 /$ & 733.5 & 515.9 & 653.3 & 799.3 & 962.9 & $1,163.8$ \\
\hline & Inversión Pública 3/ & 200.8 & 122.4 & 151.1 & 221.0 & 253.2 & 266.7 \\
\hline
\end{tabular}

\section{$1 /$ Proyectado}

21 Incluye variación de inventarios

3/ Retomada de cuentas Nacionales

FUENTE: Cuadro No. 1 